\title{
Vibrational Spectroscopy of CO in Gas-Phase Rhodium Cluster-CO Complexes
}

\author{
André Fielicke, ${ }^{\dagger}$ Gert von Helden, ${ }^{\dagger}$ Gerard Meijer, ${ }^{\dagger, l, \S}$ Benoit Simard, ${ }^{\ddagger}$ Stéphane Dénommee,${ }^{\ddagger}$ and \\ David M. Rayner*,‡ \\ FOM-Institute for Plasma Physics Rijnhuizen, Edisonbaan 14, 3439 MN Nieuwegein, The Netherlands, Department \\ of Molecular and Laser Physics, University of Nijmegen, Toernooiveld 1, NL-6525 ED Nijmegen, The Netherlands, \\ Fritz-Haber-Institut der Max-Planck-Gesellschaft, Faradayweg 4-6, D-14195 Berlin, Germany, and Steacie Institute \\ for Molecular Science, National Research Council,100 Sussex Drive, Ottawa, Ontario K1A OR6, Canada
}

Received June 25, 2003; E-mail: David.Rayner@nrc-cnrc.gc.ca

Interest in the chemistry of transition metal atoms and small clusters dispersed on insulating supports goes back many years. ${ }^{1}$ Driven by the catalytic activity of metals such as rhodium dispersed on amorphous metal oxides supports, this interest is now strengthened due to the possibility of harnessing size-specific properties in heterogeneous catalysts. New insights into the chemical properties of small deposited metal clusters have been gained from the sizeselective preparation of cluster deposits on ordered substrates as well as from characterization techniques that have a high spatial resolution such as the scanning probe microscopies. ${ }^{2,3}$

One of the techniques that is most widely used to characterize supported metal particles is infrared (IR) spectroscopy of adsorbed carbon monoxide, $\mathrm{CO}$. The stretching frequency of $\mathrm{CO}, v(\mathrm{CO})$, is highly sensitive to structure and electron density at the binding site. The interpretation of the vibrational spectra of $\mathrm{CO}$ chemisorbed on supported metal systems relies on the comparison with $v(\mathrm{CO})$ values in stable metal carbonyl compounds, on single crystal surfaces, and with atom-CO complexes in rare gas matrixes. Until now, there is no information for isolated unsaturated metal cluster carbonyls, as conventional IR spectroscopic techniques are difficult to apply for those species.

Here, we report on the vibrational spectroscopy of gas-phase rhodium cluster complexes with $\mathrm{CO}, \mathrm{Rh}_{n} \mathrm{CO}(n=6-20)$, one of the most widely studied supported transition metal systems. Spectra in the region of $v(\mathrm{CO})$ are obtained using IR multiphoton depletion (IRMPD) spectroscopy. These gas-phase studies provide fundamental insight into metal-ligand interactions and additionally allow one to distinguish between intrinsic properties and support effects in supported clusters. The experiments take advantage of the tunable, IR radiation from the free electron laser for infrared experiments (FELIX) ${ }^{4}$ which is ideal for IRMPD spectroscopy of cluster-ligand complexes. ${ }^{5}$ Briefly, the IR induced fragmentation yields of the clusters in a molecular beam are monitored under FELIX irradiation as a function of IR frequency using mass spectrometry. Details are available as Supporting Information.

In Figure 1 parts of mass spectra are shown around the mass of $\mathrm{Rh}_{6}$ obtained under FELIX irradiation at two different IR frequencies. The peak due to $\mathrm{Rh}_{6} \mathrm{CO}$, visible with $2026 \mathrm{~cm}^{-1}$ radiation is completely depleted with $1950 \mathrm{~cm}^{-1}$ radiation. The inset in Figure 1 shows the IRMPD spectrum for $\mathrm{Rh}_{6} \mathrm{CO}$. Clearly, a resonance can be seen that can be straightforwardly attributed to the $v(\mathrm{CO})$ stretching vibration of $\mathrm{Rh}_{6} \mathrm{CO}$. Similar depletion spectra have been obtained for $\mathrm{Rh}_{n} \mathrm{CO}$ with $n=6-20$. Spectra for $n=6-15$ are

† FOM-Institute for Plasma Physics Rijnhuizen.

" Department of Molecular and Laser Physics, University of Nijmegen.

\& Fritz-Haber-Institut der Max-Planck-Gesellschaft.

\$ Steacie Institute for Molecular Science.

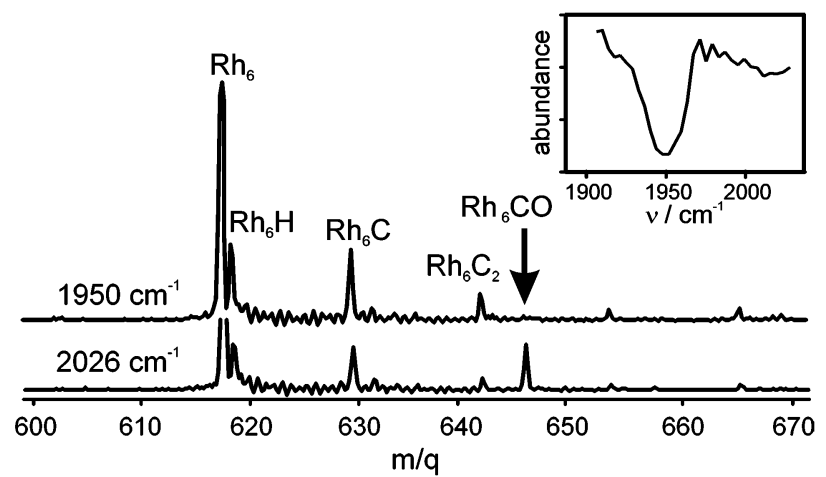

Figure 1. Mass spectra in the region of $\mathrm{Rh}_{6}$ with FELIX on $\left(1950 \mathrm{~cm}^{-1}\right)$ and off $\left(2026 \mathrm{~cm}^{-1}\right)$ the $v(\mathrm{CO})$ resonance in the $\mathrm{Rh}_{6} \mathrm{CO}$ complex. Inset shows the frequency dependence of the $\mathrm{Rh}_{6} \mathrm{CO}$ signal.
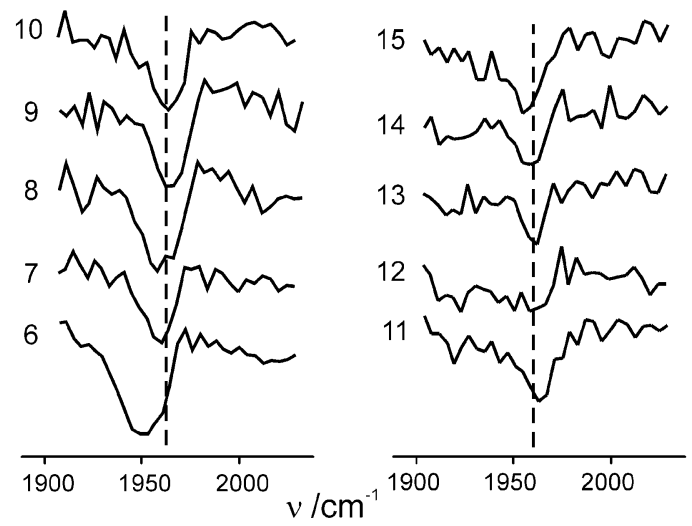

Figure 2. Infrared multiphoton depletion (IRMPD) spectra of $\mathrm{Rh}_{n} \mathrm{CO}$ cluster complexes. A dashed line at $1964 \mathrm{~cm}^{-1}$ is drawn to guide the eye.

shown in Figure 2, and the peak frequencies are summarized in Table 1 . The frequency scale is calibrated on ethylene absorptions measured in a photoacoustic cell, resulting in an absolute frequency accuracy better than $\pm 2 \mathrm{~cm}^{-1}$. $\mathrm{Rh}_{6}$ is the smallest cluster for which we can observe $\mathrm{CO}$ complexes, as the smaller $\mathrm{Rh}_{n} \mathrm{CO}$ clusters have ionization potentials (IPs) that are above the $6.42 \mathrm{eV}$ photon energy of the ArF ionization laser. Surprisingly, the $v(\mathrm{CO})$ resonance position hardly shifts in the studied cluster size range; only a small shift of $+10 \mathrm{~cm}^{-1}$ is observed in going from $\mathrm{Rh}_{6} \mathrm{CO}$ to $\mathrm{Rh}_{7} \mathrm{CO}$. For bigger clusters $v(\mathrm{CO})$ settles around $1964 \mathrm{~cm}^{-1}$. A possible exception to the invariance of $v(\mathrm{CO})$ with cluster size is $\mathrm{Rh}_{12} \mathrm{CO}$. Comparison of the spectrum of $\mathrm{Rh}_{12} \mathrm{CO}$ in Figure 2 with that of its near neighbors shows reduced absorption at $\sim 1962 \mathrm{~cm}^{-1}$ to the point that it is almost indistinguishable from the noise. There also appears to be an increase of absorption at lower frequencies. 
Table 1. CO Stretching Frequencies $\left(v(\mathrm{CO}) ; \mathrm{cm}^{-1}\right)$ for Isolated $\mathrm{Rh}_{n} \mathrm{CO}$ Complexes Together with Experimental Values of $v(\mathrm{CO})$ for CO Complexes of Surface Species and of Deposited Clusters Together with Calculated Frequencies

\begin{tabular}{|c|c|c|}
\hline $\mathrm{Rh}_{n} \mathrm{CO}$ & $n$ & $v(\mathrm{CO})$ \\
\hline isolated, this work & $\begin{array}{l}6 \\
7 \text { to } 11,13 \text { to } 20\end{array}$ & $\begin{array}{l}1950 \pm 2 \\
1960-1965^{a}\end{array}$ \\
\hline surface, low coverage ${ }^{b}$ & $\operatorname{Rh}(111),(110),(100)$ & $2015,2008,1995$ \\
\hline $\begin{array}{l}\text { on } \mathrm{Al}_{2} \mathrm{O}_{3} \\
\quad \text { (Technical Catalyst) }^{c}\end{array}$ & unknown & $\begin{array}{l}2042-2076\left(\eta_{1}\right) \\
1845-1875\left(\eta_{2}\right)\end{array}$ \\
\hline $\begin{array}{l}\text { on } \mathrm{Al}_{2} \mathrm{O}_{3} \text {, } \\
\text { highly ordered film }\end{array}$ & $5-9$ (mean size $)$ & 1999 \\
\hline $\begin{array}{l}\text { on } \mathrm{MgO}(100) \text { film, } \\
\text { size-selected deposition }\end{array}$ & 8 & 2066 \\
\hline DFT calculation ${ }^{f}$ & 3 & 2029 \\
\hline & 4 & 2065 \\
\hline
\end{tabular}

${ }^{a}$ Values for individual complexes available as Supporting Information. ${ }^{b}$ Reference 6. ${ }^{c}$ Reference $7 .{ }^{d}$ Reference $2 .{ }^{e}$ Reference $3 .{ }^{f}$ Reference 8.

The isolated $\mathrm{Rh}_{n} \mathrm{CO}$ complexes can be compared to $\mathrm{CO}$ adsorbed on clean crystalline Rh surfaces. ${ }^{6}$ There, $\mathrm{CO}$ can bind atop and in bridging positions. At low $\mathrm{CO}$ coverage $(\theta<0.1)$ the values for $v(\mathrm{CO})$ range from 1995 to $2015 \mathrm{~cm}^{-1}$ for $\mathrm{CO}$ adsorbed in the atop position, and only on $\mathrm{Rh}(100) \eta_{2}$-bridging $\mathrm{CO}$ has been found at low coverage with a $v(\mathrm{CO})$ frequency of $1875 \mathrm{~cm}^{-1}$. The position of $v(\mathrm{CO})$ is influenced by the local electronic structure of the substrate and can be understood using the classical electron donation/back-donation description of the carbonyl bond. From this model, a shift of $v(\mathrm{CO})$ to lower frequency is expected for the clusters due to the reduced coordination of the $\mathrm{Rh}$ atoms compared to that of the surface. The reduced coordination increases the electron density on the metal atom available for back-donation into the $\pi^{*}$ orbital of the $\mathrm{CO}$, which weakens the $\mathrm{C}-\mathrm{O}$ bond and reduces its stretching frequency.

Our $\mathrm{Rh}_{n} \mathrm{CO} v(\mathrm{CO})$ values indicate that, with the possible exception of $\mathrm{Rh}_{12} \mathrm{CO}, \mathrm{CO}$ occupies atop binding sites exclusively on small $\mathrm{Rh}_{n}$ clusters. At $30-65 \mathrm{~cm}^{-1}$ lower than observed for $\mathrm{CO}$ on single-crystal surfaces the $v(\mathrm{CO})$ values are low, but within the range accepted for atop-binding on bulk metal. The shift of $+10 \mathrm{~cm}^{-1}$ in going from $\mathrm{Rh}_{6} \mathrm{CO}$ to $\mathrm{Rh}_{7} \mathrm{CO}$ indicates that in very small clusters $(n<7)$ reduced metal coordination may make even more electron density available for back-donation. Although the average $\mathrm{Rh}$ atom coordination rises with increasing cluster size, $\mathrm{CO}$ is expected to find the lowest-energy binding site under equilibrium control. This is associated with the least coordinated $\mathrm{Rh}$ atom and with the lowest value for $v(\mathrm{CO})$. Surface values for $v(\mathrm{CO})$ will only be reached for much larger clusters, where the bulk ccp structure is established. Even then a single $\mathrm{CO}$ may preferentially bind to an edge and exhibit a low value for $v(\mathrm{CO})$, just as $\mathrm{CO}$ on defect sites on surfaces.

The $\mathrm{CO}$ stretch frequencies of $\mathrm{Rh}_{n} \mathrm{CO}$ are compared to work on supported $\mathrm{Rh}_{n}$ clusters in Table 1. For CO adsorbates on a technical catalyst $\left(\mathrm{Rh} / \mathrm{Al}_{2} \mathrm{O}_{3}\right)$, two different adsorption sites have been identified, atop $\left(\eta_{1}\right)$ and bridging $\left(\eta_{2}\right){ }^{7}$ The blue-shift of the $\eta_{1}$ frequency on the catalyst compared to surface values is attributable to a combination of charge transfer from the cluster to the support and adsorption of multiple $\mathrm{CO}$ molecules on the clusters. The latter effect might also be responsible for the formation of $\eta_{2}$ species on the catalyst. In our isolated $\mathrm{Rh}_{n} \mathrm{CO}$ complexes the $v(\mathrm{CO})$ values are $\sim 100 \mathrm{~cm}^{-1}$ lower than those assigned to $\mathrm{CO}$ atop-bound on the catalyst, and we find no evidence for bridge-bound $\mathrm{CO}$ in the gas phase. A special case is $\mathrm{Rh}_{12} \mathrm{CO}$ where its atypical spectrum could be due to a degree of occupation of $\eta_{2}$-bridge sites in this complex. The more recent work on Rh clusters on highly ordered $\mathrm{Al}_{2} \mathrm{O}_{3}$ films resulted in spectra that indicated the presence of cluster monocarbonyls. ${ }^{2}$ The frequencies given in the table are for conditions where the average cluster size was determined by scanning probe microscopy to be between about five and nine $\mathrm{Rh}$ atoms. It is observed that $v(\mathrm{CO})$ is relatively independent of cluster size. The size independence is consistent with our gas-phase results. The shift of $+40 \mathrm{~cm}^{-1}$ suggests significant electron transfer to the support. For $\mathrm{CO}$ bound to size-selected deposited $\mathrm{Rh}_{8}$ on $\mathrm{MgO}$ $v(\mathrm{CO})$ is $\sim 105 \mathrm{~cm}^{-1}$ higher than for the here presented value for isolated $\mathrm{Rh}_{8} \mathrm{CO}{ }^{3}$ This is possibly caused by electron transfer to the support and multiple $\mathrm{CO}$ adsorption on the supported metal clusters.

As can be seen from Table 1, the observed stretching frequency for $\mathrm{Rh}_{6} \mathrm{CO}$ is about $\sim 5 \%$ lower than the recently calculated value (B3LYP DFT calculations) for $\mathrm{Rh}_{4} \mathrm{CO}$, the largest calculated cluster. ${ }^{8}$ A scaling factor of $\sim 0.95$ would be typical for DFT calculations, but, since $v(\mathrm{CO})$ is significantly decreasing from $\mathrm{Rh}_{7} \mathrm{CO}$ to $\mathrm{Rh}_{6} \mathrm{CO}$, a further decrease might occur when going to the smaller clusters.

Future studies will focus on those smaller clusters $(n<6)$ as well as on complexes with more than one CO. Although these cannot be ionized at $6.42 \mathrm{eV},{ }^{9}$ we know that the latter are generated at high $\mathrm{CO}$ concentrations where we observe growth of the $\mathrm{Rh}_{n} \mathrm{CO}$ signal to the high-frequency side of the $\mathrm{Rh}_{n} \mathrm{CO} v(\mathrm{CO})$ depletion band due to IR driven $\mathrm{Rh}_{n}(\mathrm{CO})_{m} \rightarrow \mathrm{Rh}_{n} \mathrm{CO}$ dissociation.

It will also be possible to adapt the IR desorption experiment to study CO complexes with ionic clusters. This will provide a quantitative measurement of the effect of charge on $\mathrm{CO}$ bonding to metal clusters and will calibrate $v(\mathrm{CO})$ as a probe of charge transfer in supported clusters. Another interesting problem concerns the $\mathrm{CO}$ oxidation reactions on metal clusters. IRMPD spectroscopy could provide an analytical tool to follow the progress of such reactions.

Acknowledgment. We gratefully acknowledge the support of the Stichting voor Fundamenteel Onderzoek der Materie (FOM) in providing beam time on FELIX and the skill of the FELIX staff, in particular Dr. A. F. G. van der Meer and Dr. B. Redlich.

Supporting Information Available: Experimental details, complete table of $v(\mathrm{CO})$ frequencies (PDF). This material is available free of charge via the Internet at http://pubs.acs.org.

\section{References}

(1) J. T. Yates, J.; Duncan, T. M.; Worley, S. D.; Vaughan, R. W. J. Chem Phys. 1979, 70, 1219.

(2) Frank, M.; Bäumer, M. PCCP 2000, 2, 3723; Frank, M.; Kühnemuth, R.; Bäumer, M.; Freund, H.-J. Surf. Sci. 2000, 454, 968; Frank, M.; Bäumer, M.; Kühnemuth, R.; Freund, H.-J. J. Phys. Chem. B 2001, 105, 8569.

(3) Heiz, U.; Sanchez, A.; Abbet, S.; Schneider, W.-D. Chem. Phys. 2000, $262,189$.

(4) Oepts, D.; van der Meer, A. F. G.; van Amersfoort, P. W. Infrared Phys. Technol. 1995, 36, 297; von Helden, G.; van Heijnsbergen, D.; Meijer, G. J. Phys. Chem. A 2003, 107, 1671.

(5) Simard, B.; Dénommée, S.; Rayner, D. M.; van Heijnsbergen, D.; Meijer, G.; von Helden, G. Chem. Phys. Lett. 2002, 357, 195.

(6) Leung, L.-W. H.; He, J.-W.; Goodman, D. W. J. Chem. Phys. 1990, 93, 8328; de Jong, A. M.; Niemantsverdriet, J. W. J. Chem. Phys. 1994, 101, 10126; Wei, D. H.; Skelton, D. C.; Kevan, S. D. Surf. Sci. 1997, 381, 49 ; Linke, R.; Curulla, D.; Hopstaken, M. J. P.; Niemantsverdriet, J. W. J. Chem. Phys. 2001, 115, 8209.

(7) Rice, C. A.; Worley, S. D.; Curtis, C. W.; Guin, J. A.; Tarrer, A. R. J. Chem. Phys. 1981, 74, 6487.

(8) Mineva, T.; Russo, N.; Freund, H.-J. J. Phys. Chem. A 2001, 105, 10723.

(9) Further addition of $\mathrm{CO}$ is expected to raise the IP of the complexes, as it does in Ni clusters, cf. Parks, E. K.; Kerns, K. P.; Riley, S. J. J. Chem. Phys. 2000, 112, 3384

JA036897S 